\title{
Conservation implications should guide the application of conservation genetics research
}

\author{
Briar J. Howes* ${ }^{*}$ Richard Pither, Kent A. Prior \\ ${ }^{1}$ Ecological Integrity Branch, Parks Canada Agency, 25 rue Eddy, Gatineau, Quebec K1A 0M5, Canada
}

\begin{abstract}
Genetics research can reveal important insights into the effective management of species at risk, yet research does not often translate into meaningful management outcomes. Before engaging in genetics research, conservation practitioners should carefully consider the resulting management outcomes by identifying the potential results of the proposed research, the conservation implications of the results, whether these implications call for a change in management practices, and whether such a change is possible. We provide a decision key to aid practitioners in evaluating the merit of a particular genetics research question, and we demonstrate the use of this key with 2 example research questions.
\end{abstract}

KEY WORDS: Conservation genetics $\cdot$ Species at risk $\cdot$ Recovery planning $\cdot$ Conservation science $\cdot$ Conservation biology $\cdot$ Conservation resource allocation

\section{INTRODUCTION}

Many researchers and conservation managers have embraced the field of conservation genetics to provide insight into various management aspects of species at risk. In its early development, conservation genetics primarily involved the application of identifying genetic threats (inbreeding depression or low genetic diversity) to the persistence of a population (e.g. Bonnell \& Selander 1974, O'Brien et al. 1985). Today, the discipline of conservation genetics extends far beyond this application and includes numerous others, including species identification, designating management units across a species' range, forensics (illegal collection, disease analysis), identifying metapopulation dynamics, and obtaining valuable species biology information that may otherwise be intractable.

Conservation genetics has undoubtedly become a valuable component in the management and recovery of species at risk. Yet, while results of genetic research commonly produce conservation implications for focal species at risk, they often do not translate into management outcomes (Hogbin et al. 2000). For instance, Vernesi et al. (2008, p. 803) summarized the 2007 Interna- tional Population Genetics for Animal Conservation workshop by suggesting that 'the most frustrating conclusion to arise from [the workshop] was that few of the speakers used their data and quantitative methods to propose practical conservation solutions'. The 'disconnect' between conservation genetics research and management outcomes is also demonstrated by Moyle et al. (2003), who reviewed 181 US Endangered and Threatened species recovery plans and found that while $22 \%$ of recovery plans identified genetic threats to population persistence, there was little response to these genetic threats in the form of specific recovery or management tasks. The authors conclude that genetic data appear to play a minor and relatively ill-defined role in the recovery planning process (Moyle et al. 2003).

If genetic data play an unclear role in the recovery planning process, this raises important implications for prioritizing genetics research in the allocation of species-at-risk funding. It is clearly inappropriate, from both a species recovery perspective as well as a funding-accountability perspective, to fund research via the mandate of species recovery that does not translate into meaningful management outcomes. The apparent unclear role of genetic data in the recovery planning 
process should by no means devalue the use of molecular tools in conservation biology, but it may suggest that more careful use of molecular tools is required.

We urge managers to adopt a critical evaluation method for each proposed conservation genetics research project (and for that matter, all proposed research) aimed at contributing to the recovery of a particular species at risk. Here, we describe a decision key that can guide conservation practitioners in evaluating the utility of engaging in conservation genetics research. We then illustrate the use of this key with an example of genetics research that did translate into a practical management outcome and an example that did not translate into a practical management outcome.

\section{USING MOLECULAR TOOLS IN SPECIES RECOVERY PLANNING}

Conservation practitioners are given the challenging mandate of working to recover species at risk, often with extremely limited resources. For example, in the 2005-2006 fiscal year, the average financial support (excluding personnel) available for recovery activities to a listed species under the Canadian Species at Risk Act was less than 90000 CAD (RENEW 2006). Research is just one of many required recovery activities (e.g. land purchase, development of recovery planning documents, outreach and education) that need to be achieved with this support; thus, research funds are limited and practitioners must critically evaluate the merits of many research questions to the recovery of species at risk. Evaluating genetics metrics is simply one means available that can be used to address the research needs of conservation practitioners. However, molecular tools can be costly and they may not be as cost-effective or appropriate for the question at hand relative to more traditional tools.

Recognizing that a set of clear criteria may help to facilitate the effective use of molecular tools for applied conservation, various authors have suggested conditions for how and when molecular tools should be employed. For example, Peakall \& Sydes (1996) suggest that genetics research for species conservation is best applied to 4 particular scenarios: when it is not possible to conserve all populations and reserve design is a management option, when translocation of individuals is prescribed, when the species may be extensively clonal or inbreeding, and when the taxonomy of the species is uncertain. Alternatively, Frankham et al. (2002) suggest that genetics research for species conservation is best applied if the species' taxonomy is unclear, if the population is small and/or fragmented, if the population is subject to harvesting, and if there are unknown aspects of the species' biology.
The above criteria are useful in outlining general scenarios and conditions for when and how genetics should be employed in applied conservation. However, they do not facilitate the evaluation of a specific research question, nor do they link the merit of a particular research question to its potential conservation and management implications. Rather than a set of criteria, we suggest that the utility of a proposed genetics research project be critically evaluated using the framework of a decision key.

\section{A DECISION KEY TO EVALUATE THE CONSERVATION MERIT OF GENETICS RESEARCH QUESTIONS}

Hogbin et al. (2000) provide an excellent schematic representation for the evaluation of the conservation implications and outcomes of a genetics study. We have adapted their schematic representation to create a decision key that guides managers in evaluating the practical utility of a proposed genetic investigation (Fig. 1). Decision keys offer a dichotomous, restricted framework within which users are guided through an evaluation process. Within our decision key, users are guided to identify a specific research question, the potential research results of the question, the conservation implications of each potential result, whether or not management practices need to be altered to address each conservation implication, and finally, whether such change in management practices is possible.

In contrast to the previously described evaluation criteria (e.g. Peakall \& Sydes 1996, Frankham et al. 2002), our decision key offers a more structured evaluation process, is more user-friendly, and can be applied to questions beyond the domain of conservation genetics. The generality of our key enables conservation practitioners to assess myriad research projects from diverse fields using standardized evaluation criteria. Our decision key differs from Hogbin et al.'s (2000) original schematic representation in that it is a question-based, strictly bifurcating key based on 'Yes' or 'No' answers, and it breaks the original schematic into more discrete steps within the evaluation process. Our decision key addresses this simple yet critical question: Will results from a specific research question translate into a practical management outcome (e.g. a recovery action)?

The decision key was primarily developed for the purpose of guiding conservation practitioners with limited (but rudimentary) understanding of conservation genetics to evaluate the practical merit of a proposed research question to species conservation. That said, the key is appropriate for many other uses and users. 


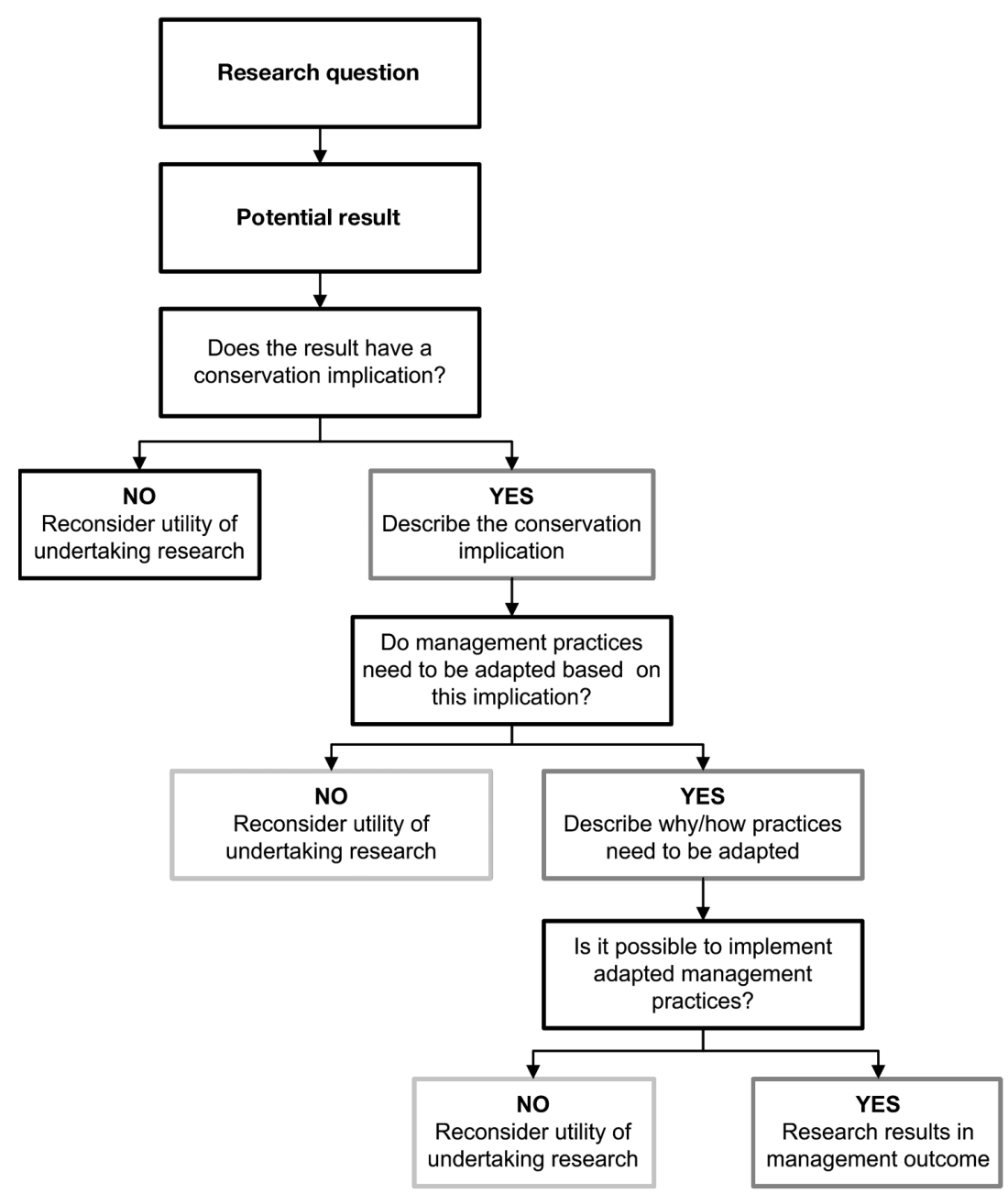

Fig. 1. Decision key to evaluate the merit of a particular genetics research question to practical management and recovery actions for species at risk (adapted from Hogbin et al. 2000) range of potential research results, where each potential result generates a new branch of the key. The user determines whether a potential result will have a conservation implication (defined as a result that informs the recovery of a species at risk), whether there is a need to adapt management practices based on this conservation implication, and finally, whether it is possible to implement the required adapted management practices. If the answer to each of these questions is 'Yes' for at least 1 potential result, then the particular research question has the potential to produce a practical management outcome, and should be a prioritized research endeavor. If not, the user should reconsider the utility of undertaking this research question at this point in time. This is not to say that the question is not valuable or that it may not need to be addressed in the future; it simply suggests that this particular research question should not be prioritized for limited conservation resources at this point in time. The use of our key is concordant with a recent call for conservation practitioners to employ a triage approach to the allocation of conservation resources, in the same manner that medical practitioners apply the triage approach to emergency medicine (Bottrill et al. 2008, McDonald-Madden et al. 2008a).
For instance, the key can be used as a point of discussion between conservation practitioners and geneticists to increase communication between the 2 groups and identify common research interests and needs for collaborative species recovery research. Additionally, the key can be used to reveal policy gaps within the current recovery planning process and knowledge gaps within and between conservation practitioners and geneticists.

The use of this key addresses 2 important components of achieving scientifically sound research objectives for conservation. First, research ideas are embedded into a question-driven, scientific framework. Second, the range of potential research results is a priori translated into potential conservation implications and practical outcomes. Use of this key begins with the identification of an appropriate research question. Based on this question, the user then identifies the

\section{Translation success: conservation genetics research that resulted in a practical management outcome}

Delineating management units for the five-lined skink

We first illustrate the use of the decision key by describing an example of conservation genetics research that resulted in a practical management outcome (Fig. 2).

The five-lined skink Plestiodon fasciatus occurs in Canada as 2 regional populations that are geographically disparate, ecologically distinct, and face different levels of threats to their persistence. If these 2 regional populations are also genetically distinct, they may warrant separate conservation status rankings and separate conservation management strategies. As such, a potentially useful research question could be: Are the 


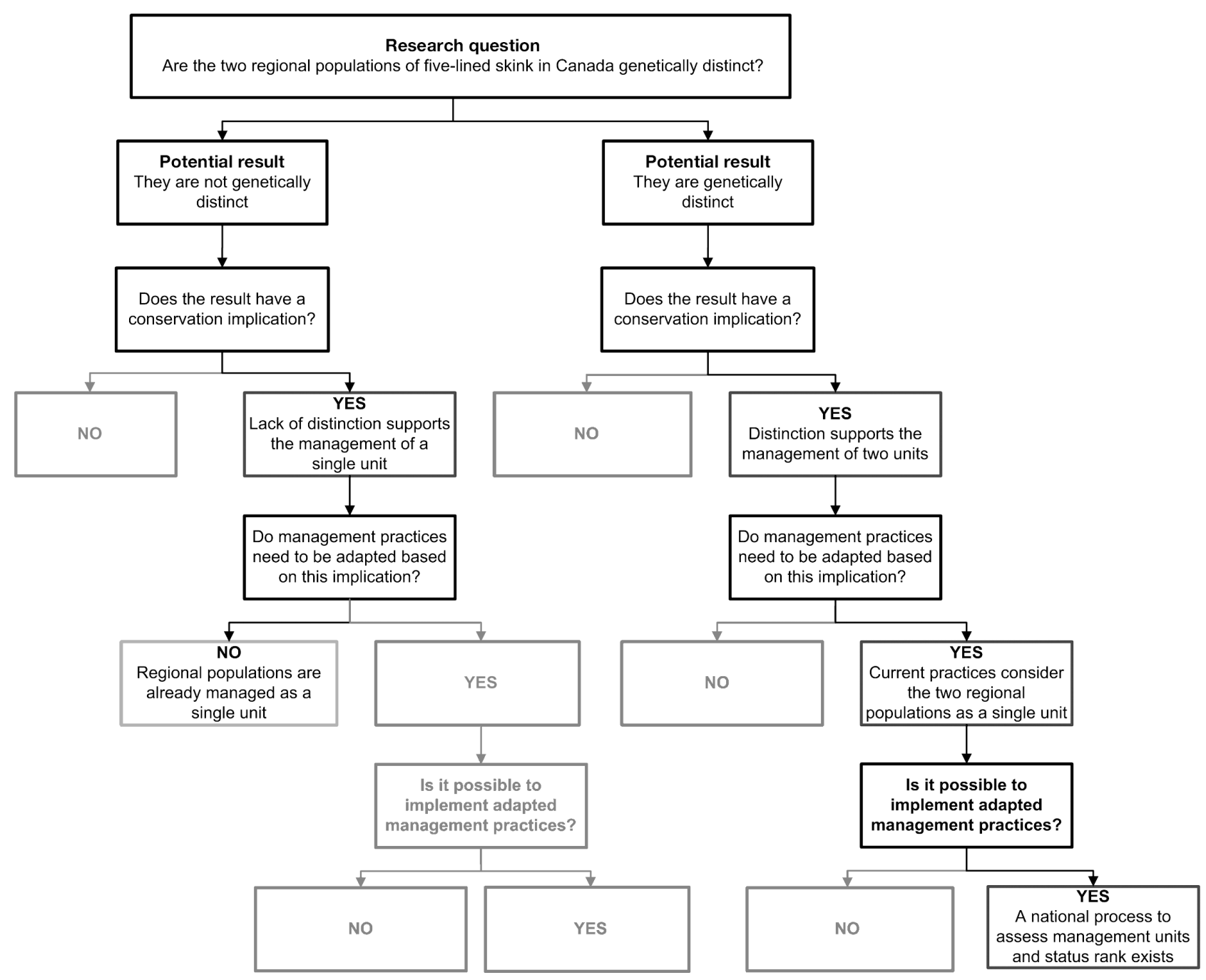

Fig. 2. Decision key to evaluate the merit of investigating whether Canada's 2 regional populations of five-lined skinks are genetically distinct

2 Canadian regional populations of five-lined skink genetically distinct?

Using our decision key, we can evaluate the potential effectiveness of this research proposal in a standardized manner. For this research question, there are 2 potential results: (1) the 2 regional populations are genetically distinct, or (2). the 2 regional populations are not genetically distinct (Fig. 2). One of these potential results leads to a conservation implication, a need to adapt current management practices based on this implication, and a feasible path forward to implement the adapted management practices. Thus, the research question is supported as a useful endeavor.

Indeed, because this research has already been completed, we can confirm that it did result in a practical management outcome. The research indicated that the 2 geographically disparate regional populations were sig- nificantly genetically differentiated according to neutral microsatellite loci. Thus, these genetic data supported the notion that the 2 regional populations should be assessed and managed as separate units. This genetic information was incorporated into the updated species assessment performed by the Committee on the Status of Endangered Wildlife in Canada (COSEWIC, the national advisory body that assesses the status of Canadian wildlife) and contributed to the decision by COSEWIC to split the designatable units of the species to reflect the 2 distinct regional Canadian populations. The split resulted in the up-listing of 1 regional population from Special Concern to Endangered, while the second regional population remains as Special Concern (COSEWIC 2007). As a result of this change in conservation status, the more imperiled series of populations will now be given higher priority for conservation action. 


\section{Lost in translation: conservation genetics research that did not result in a practical management outcome}

Assessing the genetic threat to Canadian five-lined skink populations

We now illustrate the use of our decision key by describing an example of conservation genetics research that did not result in a practical management outcome (Fig. 3).

As is the case for many Canadian reptiles, Canadian populations of the five-lined skink occur at the northern periphery of the species' range limit. It has been hypothesized that geographically peripheral populations of many species should have reduced genetic diversity relative to more centrally located populations, thereby potentially decreasing their ability to evolve in response to to environmental change and their likelihood of long-term persistence (e.g. Lande \& Shannon 1996). The hypothesis that peripheral populations do have reduced genetic diversity relative to other populations has been empirically tested (see Eckert et al. 2008 for a review), often using the (perhaps erroneous) assumption that neutral genetic variation is representative of genetic variation for quantitative traits (Pfrender et al. 2000). As such, a potentially useful research question could be: Do Canadian populations of the five-lined skink have reduced genetic diversity relative to other populations across the species' range? For this research question, there are 2 potential results: (1) Canadian populations do have reduced levels of genetic diversity relative to other populations, or (2) Canadian populations do not have reduced levels of

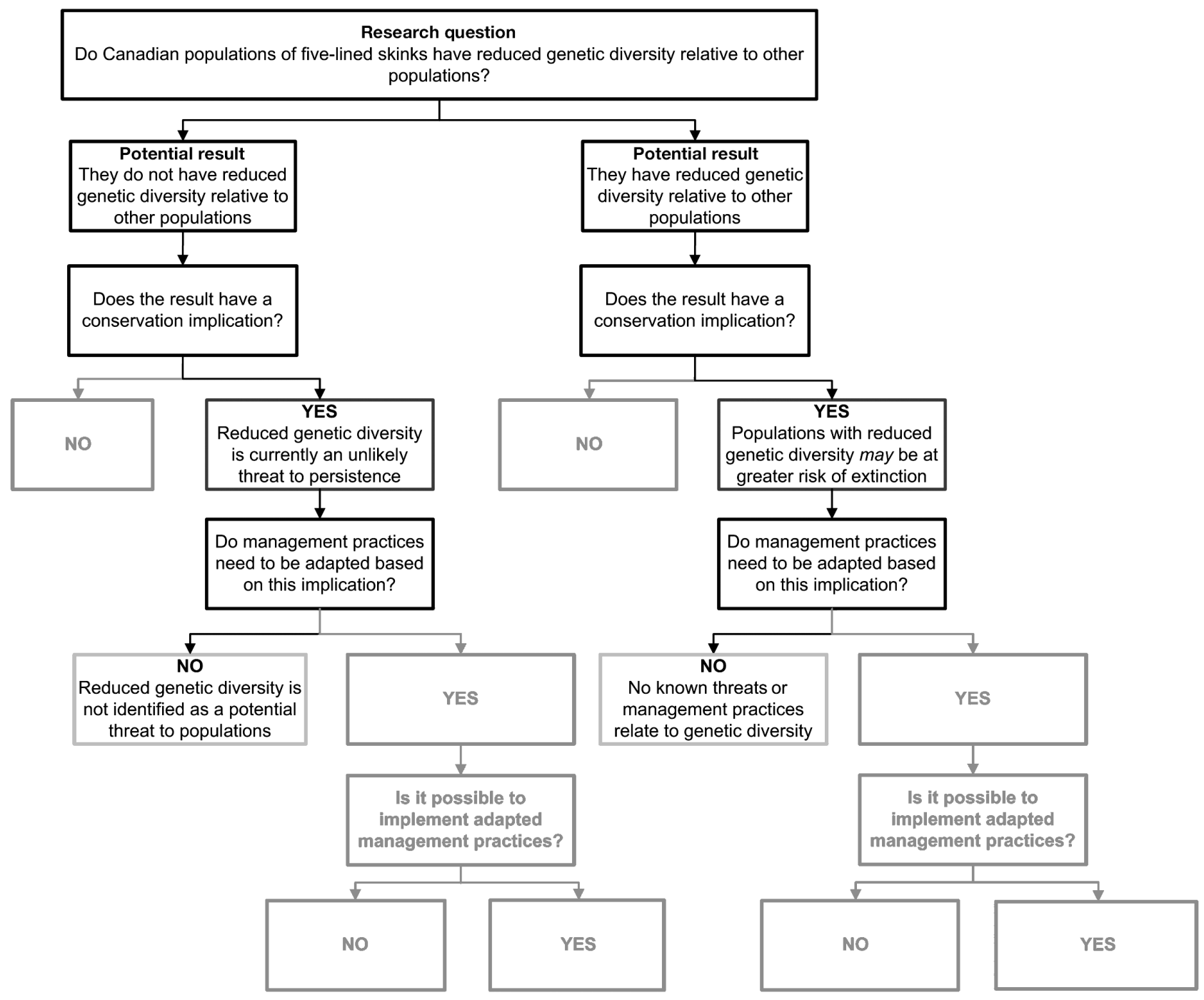

Fig. 3. Decision key to evaluate the merit of investigating whether Canada's populations of five-lined skinks have reduced levels of genetic diversity relative to other populations in the species' range 
genetic diversity relative to other populations (Fig. 3; see Howes \& Lougheed 2008).

While either potential result produces a conservation implication, neither implication calls for the need to adapt current management practices. In this particular case, there are no apparent detrimental phenotypic effects (e.g. birth defects and low juvenile survival, Madsen et al. 1999, Újvári et al. 2002; scale anomalies, Gautschi et al. 2002) that might be attributable to reduced genetic diversity following a demographic bottleneck or isolation, nor are there plans for recovery activities (e.g. re-introduction or ex situ collections) that might be informed by knowledge of the spatial distribution of genetic diversity at this point in time. Because neither potential result suggests a need to alter current management practices, the research question is not supported as a useful endeavor at this time. This is not to say that the research is not interesting or that it will not provide insight into future management decisions. Nor does it mean that conservation practitioners should not be interested in collaborating on such a project by way of intellectual or logistical contributions. It simply suggests that the research question will not presently inform management practices, and therefore it should not be prioritized for limited research funding by a conservation agency at this time.

\section{CONCLUSIONS}

Here, we have demonstrated how genetic data can either be translated into practical management outcomes, or become lost in the translation process. We have described an easy-to-use decision key to guide conservation practitioners in evaluating the utility of genetics research (or indeed any proposed research) to the recovery of species at risk. Molecular tools are one of myriad research tools available to inform recovery actions for species at risk, and practitioners must ensure that they use the right tool to address the right question. A more judicious use of molecular tools is crucial to ensuring that genetic data are better translated into practical outcomes.

Additionally, there are other actions that can help to ensure conservation genetics research is better translated into practical management outcomes. We echo the call of other authors for increased communication between conservation practitioners and academic conservation geneticists (Whitten et al. 2001, Stinchcombe et al. 2002, Moyle et al. 2003). To this end, the key described herein can be used as a point of communication between conservation practitioners and academics to identify and refine specific research questions of common interest.
We also urge academic researchers to become more involved in the process of recovery planning for species at risk. Conservation geneticists can dispel the mystique of genetics to conservation practitioners through increased communication and involvement in the recovery process. They can also guide conservation practitioners (who may not have a solid grasp of genetics) in distinguishing between statistically and biologically significant results and in translating results of genetic data to practical management outcomes. One study showed that the recovery planning process was strengthened when recovery teams involved authors from diverse affiliations, and that academic involvement in recovery planning was found to improve the utilization of biological information in recovery plans (Gerber \& Schultz 2001).

There is a growing appreciation in the field of conservation biology for the need to evaluate the effectiveness of particular conservation science research projects (e.g. Pullin \& Knight 2001, Ferraro \& Pattanayak 2006, Kapos et al. 2008). Additionally, there is increasing interest in the optimization of resource allocation in conservation biology. While some methods proposed for optimizing resource allocation in conservation biology have presented decision-support tools to prioritize resources across species (e.g. Marsh et al. 2007), the key we present is designed to guide the prioritization of species-specific research activities. Other methods proposed for optimizing resource allocation involve sophisticated modeling or cost-benefit analysis (e.g. Naidoo \& Ricketts 2006, McDonald-Madden et al. 2008b), whereas our decision key is a user-friendly decision-support tool that requires relatively little time and no modeling expertise to complete.

Ultimately, a quantitative evaluation of the effectiveness of various applications of conservation genetics to the long-term recovery of species at risk is required to assist managers in assessing when and how to use molecular tools in effective recovery planning. For instance, a systematic review of the utility of molecular tools to species recovery might address questions including: (1) How often do results from conservation genetics research projects translate into practical management outcomes? (2) What type of management decision or outcome is most informed by genetic data? A quantitative evaluation of this sort will undoubtedly be a worthwhile yet formidable task primarily because conservation consequences are rarely documented (Pullin et al. 2004). In the meantime, our proposed decision key process acts as an effective guide to aid practitioners in evaluating the merit of a genetics research question (or any research question in general) on a case-by-case basis.

In conclusion, conservation genetics is an exciting field of research, and molecular tools provide conser- 
vation practitioners with numerous applications to address a suite of research questions required for the effective management of species at risk. By no means do we wish to dissuade conservation practitioners from engaging in conservation genetics research, nor do we intend to discourage long-term or pure research supported through other funds. As an aside, we have all used molecular tools during our own academic and applied research, and greatly appreciate the powerful insights that they can provide to many aspects of conservation management. We simply urge, in an age of limited conservation resources, more careful consideration of the utility of genetic data for each particular research objective, as well as a more careful understanding of how results from genetics research may or may not translate into a meaningful management outcome. A more critical approach of engaging in conservation genetics research for species recovery will ensure that the role of genetic data in the recovery process will be more effective and that limited conservation resources will be better spent.

Acknowledgements. We acknowledge a Parks Canada postdoctoral fellowship via the Natural Sciences and Engineering Research Council of Canada (NSERC) to B.J.H., and we thank P. Nantel for valuable comments on an earlier version of this manuscript.

\section{LITERATURE CITED}

Bonnell ML, Selander RK (1974) Elephant seals: genetic variation and near extinction. Science 184:908-909

Bottrill MC, Joseph LN, Carwardine J, Bode M and others (2008) Is conservation triage just smart decision making? Trends Ecol Evol 23:649-654

COSEWIC (Committee on the Status of Endangered Wildlife in Canada) (2007) COSEWIC assessment and update status report on the five-lined skink in Canada. www.sararegistry.gc.ca

Eckert CG, Samis KE, Lougheed SC (2008) Genetic variation across species' geographical ranges: the central-marginal hypothesis and beyond. Mol Ecol 17:1170-1188

Ferraro PJ, Pattanayak SK (2006) Money for nothing? A call for empirical evaluation of biodiversity conservation investments. PLoS Biol 4:e105

Frankham R, Ballou JD, Briscoe DA (2002) Introduction to conservation genetics. Cambridge University Press, Cambridge

Gautschi B, Widmer A, Joshi J, Koella JC (2002) Increased frequency of scale anomalies and loss of genetic variation in serially bottlenecked populations of the dice snake, Natrix tessellate. Conserv Genet 3:235-245

Gerber LR, Schultz CB (2001) Authorship and the use of biological information in endangered species recovery plans. Conserv Biol 15:1308-1314

Editorial responsibility: Mike Bruford, Cardiff, UK
Hogbin PM, Peakall R, Sydes MA (2000) Achieving practical outcomes from genetic studies of rare Australian plants. Aust J Bot 48:375-382

> Howes BJ, Lougheed SC (2008) Genetic diversity across the range of a temperate lizard. J Biogeogr 35:1269-1278

Kapos V, Balmford A, Aveling R, Bubb P and others (2008) Calibrating conservation: new tools for measuring success. Conserv Lett 1:155-164

> Lande R, Shannon S (1996) The role of genetic variation in adaptation and population persistence in a changing environment. Evolution 50:434-437

Madsen T, Shine R, Olsson M, Wittzell H (1999) Restoration of an inbred adder population. Nature 402:34-35

Marsh H, Dennis A, Hines H, Kutt A and others (2007) Optimizing allocation of management resources for wildlife. Conserv Biol 21:387-399

McDonald-Madden E, Baxter PWJ, Possingham HP (2008a) Subpopulation triage: how to allocate conservation effort among populations. Conserv Biol 22:656-665

McDonald-Madden E, Baxter PWJ, Possingham HP (2008b) Making robust decisions for conservation with restricted money and knowledge. J Appl Ecol 45:1630-1638

Moyle LC, Stinchcombe JR, Hudgens BR, Morris WF (2003) Conservation genetics in the recovery of endangered animal species: a review of US endangered species recovery plans (1977-1998). Anim Biodivers Conserv 26:85-95

> Naidoo R, Ricketts TH (2006) Mapping the economic costs and benefits of conservation. PLoS Biol 4:e360

O'Brien SJ, Roelke ME, Marker L, Newman A and others (1985) Genetic basis for species vulnerability in the cheetah. Science 227:1428-1434

Peakall R, Sydes MA (1996) Defining priorities for achieving practical outcomes from the genetic studies of rare plants. In: Stephens S, Maxwell S (eds) Back from the brink. Refining the threatened species recovery process. Surrey Beatty and Sons, Sydney, p 119-129

> Pfrender ME, Spitze K, Hicks J, Morgan K, Latta L, Lynch M (2000) Lack of concordance between genetic diversity estimates at the molecular and quantitative-trait levels. Conserv Genet 1:263-269

Pullin AS, Knight TM (2001) Effectiveness in conservation practice: pointers from medicine and public health. Conserv Biol 15:50-54

Pullin AS, Knight TM, Stone DA, Charman K (2004) Do conservation managers use scientific evidence to support their decision-making? Biol Conserv 119:245-252

RENEW (2006) Recovery of nationally endangered wildlife in Canada, annual report no. 16. Environment Canada, Ottawa

Stinchcombe J, Moyle LC, Hudgens BR, Bloch PL, Chinnadurai S, Morris WF (2002) The influence of the academic conservation biology literature on endangered species recovery planning. Conserv Ecol 6:15

Újvári B, Madsen T, Kotenko T, Olsson M, Shine R, Wittzell H (2002) Low genetic diversity threatens imminent extinction for the Hungarian meadow viper (Vipera ursinii rakosiensis). Biol Conserv 105:127-130

- Vernesi C, Bruford MW, Bertorelle G, Pecchioli E, Rizzoli A, Hauffe HC (2008) Where's the conservation in conservation genetics? Conserv Biol 22:802-804

Whitten T, Holmes D, MacKinnon K (2001) Conservation biology: a displacement behavior for academia? Conserv Biol $15: 1-3$

Submitted: December 2, 2008; Accepted: April 21, 2009 Proofs received from author(s): August 7, 2009 